\title{
The effects of high intensity white noise on the sleep pattern of the rat'
}

\author{
H. B. VAN TWYVER, UNIVERSITY OF FLORIDA ${ }^{2}$, R. A. LEVITT, UNIVERSITY OF PITTSBURG
}

R. S. DUNN, UNIVERSITY OF FLORIDA

EEG's were recorded from 5 rats during $24 \mathrm{hr}$. of continuous high intensity white noise following a $24 \mathrm{hr}$. baseline period, to determine the effect of this treatment upon the sleep pattern. It was found that the treatment reduced the amount of paradoxical sleep (PS) although there was no recovery during post treatment recording as reported by Khazan E Sawyer (1963) for the rabbit. Total amounts of sleep did not change, although significant changes in mean length and frequency of the sleep episode were found. It is thought that the observed PS decrement was secondary to the reduction in sleep episode length.

Khazan \& Sawyer (1963) reported almost complete deprivation of paradoxical sleep (PS) in the rabbit using a high intensity white masking noise. On the day following the sound treatment a rebound recovery of PS was shown suggesting that PS may have drive characteristics. A similar rebound recovery of PS has been shown in the rat, using another means of deprivation (Levitt, 1966, in press).

The present study attempted to replicate Khazan \& Sawyer's experiment using the rat. A detailed analysis of the effects of high intensity white noise on the sleep pattern was also performed. Changes in the length and frequency of the sleep episode as well as changes in total amounts of slow-wave sleep (SWS) and PS were studied.

Method

Bipolar cortical electrodes (right frontal to occipital) were surgically implanted on the dura of five adult, male, Long-Evans rats. Following a recovery period of one week, the experiment was begun. The sleep cycle was recorded continuously for three days using a Grass III-D electroencephalograph. Room temperature was maintained at $70 \pm 2^{\circ} \mathrm{F}$ and the lights were on $12 \mathrm{hr}$. and off $12 \mathrm{hr}$. each day. Day one served as a baseline measure. During day 2, a "white" noise measuring $92 \mathrm{~dB}$ served as the experimental treatment (amuient room noise measured $67 \mathrm{~dB}$ ). This was followed by a third day of post-treatment recording.

Each minute was scored as waking, SWS or PS according to which phase was most prevalent during the period (Swisher, 1962). The data were tabulated in terms of total amounts, frequency and length of both SWS and PS episodes for the three days.

\section{Resulis and Discussion}

The major finding of this experiment was a significant reduction in PS during the high intensity sound treatment with no decrease in amount of SWS. Table 1 illustrates this finding. Comparison of days 1 and 2 showed a statistically significant decrease in percentage of PS ( $t$ test for correlated means). However, the expected rebound of PS was not found on day 3. Percentage of PS on this day was significantly less than day 1 but not different from day 2. (Since these comparisons and other similar comparisons in this study are notorthogonal, only ts with $p<.01$ are reported as significant.)

The mean sleep episode length was $6.33 \mathrm{~min}$. during day 1. PS occurred in bursts with a mean duration of $2.68 \mathrm{~min} .$, only slightly longer than the figure of $2.1 \mathrm{~min}$. reported for the rat by Roldan \& Weiss (1963). The rats spent $23 \%$ of total sleep time in PS during baseline recording, a value which is consistent with Svorad (personal communication, 1965).

Further analysis showed a statistically significant decrease in mean length of the sleep episode during day 2 with an associated increase in number of episodes. (An episode is defined as the period extending from sleep onset to reawakening.) This finding suggests that decreases in PS due to sound treatment may have been secondary to a decrease in sleep episode length. In this study, high intensity white noise reduced the mean length of the sleep episode and decreased total amounts of PS. Other data (Webb, personal communication, 1966), indicate that the probability that a sleep episode will include some amount of PS varies directly with its length, and PS rarely occurs during the first $2 \mathrm{~min}$. of an episode. During sound treatment, the rats tended to sleep in shorter, more frequent bursts maintaining a fairly constant amount of SWS. These data suggest that PS depends upon a minimum run of SWS for emergence, longer runs being associated with a higher probability of PS.

The rebound recovery of PS as reported by Khazan \& Sawyer was not obtained. Future experiments of this type will require longer post-treatment recording to determine whether the reduction in PS is permanent or not.

Table 1. Summary of SWS and PS data.

Asterisks indicate that value was significantly different from day 2 value in center column $(p<.01)$.

\begin{tabular}{lcccc} 
& Day 1 & Day 2 & Day 3 \\
\hline Mean percent total sleep & .44 & .43 & .43 \\
Mean percent PS of total sleeptime & $.23^{* *}$ & .16 & .16 \\
Mean No. of sleep episodes & $104^{* *}$ & 135.8 & $116.4 * *$ \\
Mean length of sleep epi sodes (min.) & $6.33^{*}$ & 4.54 & $5.56^{* *}$ \\
Mean length of PS bursts (min.) & 2.68 & 2.20 & 2.23 \\
\hline
\end{tabular}


During this experiment the Ss were watched continuously by $\mathrm{E}$. No behavioral seizures were noted. While we cannot completely rule out the possibility of permanent auditory damage as a factor in this study, during post experimental testing it was possible to elicit an auditory startle response in each rat.

Sleep can be considered a need or drive state. Annoying or noxious stimuli which tend to arouse the $S$ may balance against this drive, resulting in the shorter sleep episodes observed on day 2. The drive state, however, continues and the number of episodes increases as a result. The ability of the rat to obtain normal amounts of SWS under the extreme conditions of this experiment is noteworthy.

\section{References}

Khazan, N., \& Sawyer, C. H. "Rebound" recovery from deprivation of paradoxical sleep in the rabbit. Proc. Soc. Exp. Biol. Med., 1963, 114, 536-539.

Levitt, R. A. Paradoxical sleep: activated by sleep deprivation. J. comp. physiol. Psychol., in press.

Roldan, E., \& Weiss, T. Comparative study of sleep cycle in rodents. Experientia, 1964, 20, 280-283.

Swisher, J. Manifestations of "activated" sleep in the rat. Science, $1962,138,1110$.

\section{Notes}

1. Supported by NIH Grant No. MH 03881-05 to Dr. W. B. Webb, to whom we express our gratitude.

2. Center for Neurobiological Sciences trainee. 